\title{
Neoliberalismo y gobernanza territorial: propuestas y reflexiones a partir del caso de Chile
}

\section{Neoliberalism and territorial governance: proposals and reflections based on the case of Chile}

\author{
Beatriz Bustos Gallardo', Michael Lukas², Caroline Stamm³ \\ y André Torre ${ }^{4}$
}

\begin{abstract}
RESUMEN
El artículo analiza la gobernanza y sus nuevos mecanismos desde la perspectiva de la economía política espacial, en el caso de Chile, abordando tres dimensiones clave: los contextos y proyectos socio-políticos, los dispositivos de territorialización y re-escalamiento, y las técnicas, prácticas e instrumentos de intervención territorial. Después de una revisión teórica y contextual, el articulo presenta dos casos de mecanismos de gobernanza territorial: la Mesa del Salmón (región de Los Lagos) y CREO Antofagasta (región de Antofagasta), demostrando que estos mecanismos no nacen para resolver problemas de fondo del proyecto neoliberal o repensar los territorios de forma colectiva, sino para dar continuidad al modelo de producción imperante y restaurar la legitimidad de sectores y empresas extractivistas, en situación de crisis. Concluye sobre la necesidad de dejar una mirada neutra y avanzar hacia una lectura crítica de la gobernanza que considere, en el análisis, el contexto y las relaciones de poder.
\end{abstract}

Palabras clave: Gobernanza, territorio, proyecto neoliberal, dispositivos, crisis

\begin{abstract}
The paper analizes governance and its new mechanisms from the perspective of the spatial political economy for the case of Chile, examining three key dimensions» the context and its socio-political projects, the dispositifs (devices) of territorialization and re-scaling, and, the techniques, practices and tools of territorial intervention. After a theoretical and contextual review, the paper discusses two cases of territorial governance : the Salmon Task Force (Los Lagos Region) and CREO Antofagasta (Antofagasta Region), showing that these mechanisms are not created to solve the core problems of the neoliberal project, or to rethink in a collective manner the territories, but, to give continuity to the prevailing more of production and to restore legitimacy to extractive sectors and firms in times of crises. The paper concludes arguing the need to move away from a neutral understanding of governance toward a critical understanding that considers the context and power relations.
\end{abstract}

Keywords: Governance, territory, neoliberal project, dispositifs, crisis.

\footnotetext{
Departamento de Geografía, Facultad de Arquitectura y Urbanismo, Universidad de Chile, Chile, bibustos@uchilefau.cl Departamento de Geografía, Facultad de Arquitectura y Urbanismo, Universidad de Chile, Chile, mlukas@uchilefau.cl Instituto de Estudios Urbanos y Territoriales, Pontificia Universidad Católica de Chile, Chile, castamm@uc.cl Université Paris-Saclay, UMR SAD-APT, INRA - Agroparistech, Francia, torre@agroparistech.fr
} 


\section{Introducción}

En las últimas dos décadas, los términos gobernanza y gobernanza territorial han adquirido popularidad en las más diversas ciencias sociales. Con un origen en las ciencias políticas y económicas, hoy día se usa la gobernanza en disciplinas como la geografía, la sociología, la antropología, la administración pública y las ciencias económicas (Bridge \& Perreault, 2008; Jordan, 2008; Bevir, 2012; Torre, 2016). Más allá del uso académico del término, también se habla de gobernanza en circuitos de política pública y las recomendaciones de organismos de cooperación internacional para mejorar la gestión estatal. Siendo la gobernanza un término polisémico, el acuerdo común sobre su contenido básico es que gobernanza va más allá de gobierno (unilateralidad del Estado para la toma de decisiones sobre materias de interés público) (Bevir, 2012; Lukas, 2019). Se habla de gobernanza entonces para referirse a la interacción entre los sectores públicos, privados y la sociedad civil en la organización de algún asunto de interés colectivo y de gobernanza territorial cuando este asunto está vinculado al desarrollo territorial, o en las palabras de Torre (2016: 9), "como el conjunto de los procesos y dispositivos por los cuales los integrantes o los actores de diferentes tipos (productivos, asociativos, particulares, representantes de los integrantes o de las colectividades locales...) contribuyen a la elaboración, tanto concertada como conflictiva, de proyectos comunes para el desarrollo futuro de los territorios".

En Chile, en las últimas dos décadas, varios nuevos mecanismos de gobernanza territorial han emergido y el discurso de gobernanza está de moda tanto en el sector público como en el sector privado (Delamaza \& Thayer, 2016; Figueroa \& Chia, 2016). Encontramos nuevos mecanismos a nivel local, regional y nacional que a veces tienen enfoques más sectoriales, a veces enfoques territoriales integrales. Como ejemplos podemos mencionar las corporaciones para el desarrollo local en comunas como Santiago, Pudahuel y Huechuraba; a nivel regional la Mesa del Salmón en la región de Los Lagos; a nivel metropolitano la iniciativa CREO Antofagasta en la Región de Antofagasta; y a nivel nacional la iniciativa Plan 2030 del Ministerio de Obras Públicas. De una u otra forma todas estas iniciativas buscan instalar nuevos mecanismos de diálogo entre los sectores públicos, privados y la sociedad civil a través de la instalación de nuevas prácticas de moderación, cooperación y toma de decisiones.

Al revisar diversos trabajos y publicaciones sobre gobernanza surgen miradas críticas y debates tanto sobre el proceso en sí, como los resultados (Perreault, 2005, Duffy, 2006, McCarthy, 2012). También existen publicaciones que desarrollan metodologías para establecer tipologías de formas de gobernanza y para analizar y evaluar instancias y procesos de gobernanza (Nuissl et al., 2012; Chia, Rey-Valette et al., 2016). Lo que muchos de estos trabajos tienen en común es su raíz epistemológica en el individualismo metodológico, la teoría de la elección racional y, en menor medida, en la teoría de las instituciones. Mientras este anclaje le da fortaleza para la descripción detallada de la interacción entre actores, nuevos instrumentos y el desarrollo temporal de las cambiantes constelaciones de actores a nivel local, estos enfoques fallan en obtener una explicación analítica más profunda tanto de la emergencia de nuevas formas de gobernanza como de sus resultados, en distintas escalas. En este sentido, enfocarse de forma directa en la interacción entre actores, instituciones y procesos de toma de decisión en casos concretos, sin problematizar procesos históricos, económicos y políticos en otras escalas temporales y sociales, ni las relaciones de poder inherentes, lleva a reproducir un problema que Renate Mayntz (2005) detectó para 
la teoría de la gobernanza en general: la suposición que los (nuevos) esquemas de gobernanza emergen para, y serían capaz de, resolver problemas (el así llamado problem solving-bias).

En este trabajo, problematizamos el análisis de la gobernanza y de sus nuevos mecanismos desde la perspectiva de la economía política espacial, en el caso de Chile, abordando conceptualmente tres dimensiones clave para, por un lado, profundizar el poder explicativo de los análisis, y por el otro, proveer elementos para realizar estudios comparativos de gobernanza territorial. Las tres dimensiones son: (1) los contextos y proyectos socio-políticos, (2) los dispositivos de territorialización y re-escalamiento y (3) las técnicas, prácticas e instrumentos de intervención territorial. Estas dimensiones se constituyen de manera simultánea y dialéctica, en un proceso contínuo de interacción entre actores territorio y acciones.

Primero, argumentamos que es necesario entender en qué contexto socio-político y económico se desarrollan los mecanismos de gobernanza territorial, pues éste define las relaciones entre el Estado, el mercado y la sociedad civil. En nuestro caso de estudio el contexto principal es el neoliberalismo, tanto como teoría económica, ideología y como práctica de implementación de un proyecto político-económico específico. Segundo, la gobernanza territorial se inserta dentro de dispositivos de territorrialización y re-escalamiento, que en el caso de Chile identificamos como las políticas de regionalización y de (de-)centralización. Lejos de ser entidades coherentes en términos históricos, culturales o físicos, tanto las regiones chilenas como sus municipalidades son el resultado de un proceso político-económico específico enmarcado en estrategias de glocalización (Mansfield, 2001) y, en este sentido, son parte de proyectos y estrategias estatales espaciales de bloques históricos específicos. Tercero, hay que abordar las técnicas, prácticas e instrumentos que se implementan, ocupan y cambian para, de una u otra forma, articular la interacción entre distintos actores en el territorio. Es en esta dimensión donde - en Chile - vemos la emergencia de nuevas formas de gobernanza que buscan mayor interacción, coordinación y participación pública-privada, tales como Mesas Redondas Ambientales, Planes Estratégicos, Planes Maestros, o, Foros Híbridos, figuras que emergen como alternativa a técnicas, prácticas e instrumentos de gobernanza territorial tradicionales.

El artículo se estructura en cuatro secciones. Tras esta introducción, en la sección dos, presentamos una revisión de la literatura sobre gobernanza territorial, para luego proponer la consideración de los contextos y proyectos socio-políticos, los dispositivos de territorialización y re-escalamiento y las técnicas, prácticas e instrumentos de intervención territorial rescatando aportes de la economía política espacial, teoría del Estado y conceptualizaciones sobre relaciones de poder. En la sección tres, explicamos el proceso de neoliberalización territorial en Chile y sus dispositivos de territorialización y re-escalamiento, en específico las políticas de regionalización y descentralización. La sección cuatro describe dos casos ubicados en las Regiones de Antofagasta (Plan CREO Antofagasta) y Los Lagos (Mesa del salmón), donde mediante la revisión de un mecanismo de gobernanza identificado, demostramos cómo el proceso y resultado se explican mejor al considerar las tres dimensiones propuestas, así evitando el problem-solving bias de gran parte de la teoría de la gobernanza. El artículo termina, en la sección cinco, con una discusión sobre los desafíos conceptuales y metodológicos que esta propuesta implica para avanzar en los estudios de gobernanza territorial en Chile. 


\section{Gobernanza territorial entre proyectos políticos, dispositivos y poder}

\subsection{El concepto de gobernanza}

En un primer sentido, se usa el término de gobernanza para referirse a "nuevas" formas de organización social e interacción política, en nuestro caso con vista al desarrollo territorial. En un periodo de globalización, expansión neoliberal y el proceso asociado de transformación y re-escalamiento del estado-nación, se observa alrededor del mundo, la emergencia de nuevas formas de deliberación, participación y toma de decisión acerca de problemas de interés colectivo (Bevir, 2012), sea a través de asociaciones públicas-privadas para la provisión de infraestructura, mesas redondas para resolver problemas ambientales o la recuperación de barrios urbanos degradados con participación de la sociedad civil. Las antiguas formas jerárquicas, en que el Estado central era el gestor de asuntos públicos, se ven acompañadas por formas más horizontales de coordinación, en distintos niveles, desde lo local a lo supra-nacional. Es en este contexto que se usa el término de gobernanza para referirse a la totalidad de estas "nuevas" formas horizontales de coordinación, cooperación o, en un sentido más crítico, cooptación. En otras palabras, para muchos autores en este sentido estamos viviendo en la época de la gobernanza (De Mattos, 2004; Jordan, 2008; Lukas, 2019).

Una segunda noción de gobernanza usa el término en un sentido prescriptivo para indicar formas y arreglos de cómo "se debería" organizar la deliberación, coordinación y toma de decisiones entre distintos actores. Aquí se parte de la base que en un mundo inter-conectado ni el Estado ni el sector privado son capaces de resolver asuntos de interés colectivo, cada vez más complejos, por sí solos y que hacen falta mecanismos de coordinación horizontal y vertical. Gobernanza en este sentido es un término para "un modelo deseado de interacción pública-privada y cooperación" (Pierre, 2005: 452). La noción prescriptiva de gobernanza es particularmente popular en los círculos de las políticas públicas y los organismos de cooperación internacional. Tanto la "Campaña global por la buena gobernanza urbana" de ONU-Habitat o la Cities Alliance proponen criterios para una gobernanza nueva y efectiva para resolver problemas de carácter urbano y territorial (Lukas, 2019).

En una tercera noción, gobernanza es un concepto analítico y una perspectiva de investigación. Las nuevas formas horizontales de interacción entre distintos actores públicos y privados en este contexto son solamente una forma en que se ejerce la gobernanza en la práctica. Como perspectiva analítica, la gobernanza no tiene ningún prejuicio sobre quienes son o deberían ser los actores que participan en la organización de asuntos de interés colectivo, ni sobre su dirección en términos de valores u objetivos (Pierre, 2005). Un ejemplo de una conceptualización que busca hacerse cargo de la complejidad de los procesos de gobernanza territorial y hasta propone una secuencia metodológica para su análisis, es la de Chia et al. (2016). Para comprender nuevos "instrumentos de gobernanza", los autores proponen considerar la institucionalidad existente, actores tradicionales y nuevos, redes entre actores, representaciones de problemáticas y controversias entre actores y sus intereses, el rol del conocimiento y el intercambio de información, entre otros elementos. Sin duda, la gran fortaleza de estas propuestas (Nuissl et al., 2012) radica en proveer marcos heurísticos para abordar la complejidad de los procesos de gobernanza, lo que estas propuestas en cambio no son capaces de explicar, por su raíz epistemológica en el 
individualismo metodológico, la teoría de la elección racional y en la teoría de las instituciones, es la relación de los nuevos mecanismos de gobernanza con procesos político-económicos en otras escalas espacio-temporales.

\subsection{Investigaciones sobre gobernanza y gobernanza territorial en Chile}

Si bien en Chile el concepto de gobernanza se ha difundido en los últimos años, ya sea en la literatura como en documentos oficiales y discursos políticos, en una primera etapa fue usado en paralelo y a veces confundido con el de gobernabilidad. Como lo destaca Boisier, "estábamos en verdad acostumbrados a un concepto propio de la macro política, la "gobernabilidad del sistema" (Boisier, 2009:14), que hacía alusión a las posibilidades de acción resultantes de la correlación entre las variables que controla el gobierno y las que no controla. Habitualmente la gobernabilidad es enfocada en términos de la capacidad técnica y la consistencia moral de los equipos gobernantes". El uso de este concepto de gobernabilidad se ubica dentro del contexto de la transición democrática chilena, y más ampliamente latinoamericana. Revela la preocupación central hacia la capacidad de gobernar en el marco de la redefinición post-dictadura de las relaciones entre gobierno y sociedad. Esta confusión tiene efectos en los procesos, mostrando el objetivo principal de mantener el control y el orden social más que de cambiar el sistema de decisión en sí y de compartir el poder con nuevos actores. A nivel epistemológico implica poner énfasis en la democracia y la participación ciudadana, a través de conceptos como la gobernanza democrática, dejando en segundo plano la pregunta de cómo y quién toma la decisión final.

El concepto de gobernanza ha sido abordado en Chile sobre todo en el ámbito urbano y metropolitano. En su dimensión analítica, identificamos dos líneas de análisis. La primera analiza la gobernanza desde la perspectiva de la globalización y de las transformaciones económicas que afectan a las grandes ciudades, incluyendo Santiago de Chile (De Mattos, 2004). En esta misma línea, se han discutido las implicaciones de la gobernanza neoliberal en las ciudades, con una nueva organización territorial en nodos y redes y la progresiva financiarización de los negocios inmobiliarios, entre otros (De Mattos, 2014). La segunda adopta otra escala y se enfoca en las relaciones de poder, a través de la puesta en la agenda y de la toma de decisión en el contexto neoliberal en el Chile postdictadura. Barton (2008) adopta una postura crítica y cuestiona, en Chile, las relaciones de poder creadas bajo el liderazgo y la gestión urbana neoliberal. Según este autor, la gobernanza urbana no es un problema técnico o la búsqueda de más participación para legitimar los proyectos urbanos, sino que "se relaciona con la forma en que las relaciones de poder son creadas y recreadas por hegemonías urbanas en su desarrollo de estrategias coactivas" (p. 427). El estudio de Hidalgo y Zunino (2011) destaca la capacidad diferenciada de incidir de los actores y por consecuencia de la operatoria del poder en los procesos de desarrollo urbano. Estos estudios apuntan a tomar en cuenta las relaciones de poder entre los actores para entender y analizar la gobernanza en el contexto neoliberal chileno. En contrapunto, pocos trabajos se han enfocado en Chile en la gobernanza en contextos no urbanos y fuera de Santiago, y aquellos, a diferencia de los estudios urbanos y metropolitanos, no han cuestionado la relación con el neoliberalismo, los dispositivos de territorialización y los procesos de re-escalamiento.

El concepto de gobernanza territorial ha sido utilizado en el caso chileno sobre todo para caracterizar la gobernanza a escala sub-nacional y más precisamente la gobernanza regional. El estudio publicado por el RIMISP Centro Latinoamericano para el Desarrollo Rural (Serrano, 2011) 
define la gobernanza territorial como "una gobernanza subnacional para el desarrollo de los territorios mediante la articulación de diversos actores territoriales, entre ellos el Estado (gobernanza multinivel vertical), la sociedad civil, las agencias públicas localizadas territorialmente y el sector privado (gobernanza multinivel horizontal), en un contexto en el cual, el gobierno regional está enfocado en las oportunidades de los territorios, estimulando el crecimiento económico con inclusión social" (p.10). La difusión del enfoque de la gobernanza busca así romper con dinámicas sectoriales a favor de dinámicas territoriales, pero en esto haciéndose eco de las nociones prescriptivas y reflejando el problem-solving bias de la teoría de la gobernanza, identificado por Mayntz (2005). No es un hecho irrefutable que la región opera como territorio y que su gobierno busca reconciliar crecimiento económico con inclusión social. Lo que argumentamos en este artículo es que la creación de la región desde luego ha respondido a una dinámica neoliberal territorial, es decir funciona como dispositivo que territorrializa el proyecto neoliberal en el espacio, produciendo un contexto en que ventajas comparativas regionales y locales pueden ser explotados por empresas nacionales y transnacionales, fomentando un proceso y una política de glocalización y una "empresarialización del territorio" (Fløysand, Barton et al., 2010). Es en este contexto que se puede entender que la región no fue pensada como espacio de toma de decisión de actores presentes en el territorio sino para administrar la política neoliberal existente; ahí la necesidad de desfetichizar la región como territorio y la gobernanza territorial como independiente de este proyecto y estas estrategias estatales espaciales.

Si bien la región es un territorio, es solamente un tipo de territorio, al cual se superponen otros. Trabajos más recientes salen de la dimensión regional de la gobernanza para abordar el territorio, más allá del ámbito político-administrativo de la región. Delamaza introduce en un artículo reciente publicado en 2016 con Thayer el concepto de territorio, entendido en su aceptación geográfica como una construcción social. La gobernanza territorial permitiría así una mejor adecuación entre las políticas públicas y las necesidades territoriales generando un cambio en el contexto centralista chileno. Como lo señala, este "cambio orientado a la gobernanza territorial remite a las capacidades de relacionamiento de los actores del proceso, para los que muchas veces no se cuenta con institucionalidad adecuada, especialmente en el ámbito regional" (p. 141). Delamaza y Thayer cuestionan las demarcaciones administrativas regionales en relación a demarcaciones más subjetivas (que califican como territorios) mostrando que la división regional no agota la consideración territorial necesaria para la gobernanza. De la misma manera, el conjunto de artículos publicados en el número 53 de la Revista de Geografía de Valparaíso, coordinado por Rodrigo Figueroa y Eduardo Chía, propone una contribución al análisis de la gobernanza territorial en Chile, a partir de un marco teórico francófono. Los textos del número se enfocan en los instrumentos de gobernanza territorial, en los aprendizajes y en el papel de conflictos en los procesos de gobernanza territorial a varias escalas territoriales: desde los clusters, hasta lo metropolitano y lo local. Sin embargo, discuten los instrumentos existentes a la luz del concepto de gobernanza pero no profundizan sobre la dimensión del poder y las lógicas neoliberales subyacentes a la conformación territorial chilena.

\subsection{La gobernanza territorial neoliberal: proyectos socio-políticos, dispositivos y poder}

En este apartado nos interesa desarrollar una aproximación teórica que permita relacionar conceptualmente procesos, mecanismos e instrumentos de gobernanza territorial con aspectos 
político-económicos que ocurren en otras escalas y con otras temporalidades. Es para esto que proponemos tres dimensiones en que procesos y mecanismos de gobernanza territorial deben ser analizados: los contextos y proyectos socio-políticos, los dispositivos de territorialización y re-escalamiento y las técnicas, prácticas e instrumentos de intervención territorial (véase Tabla 1).

Con la noción de "contextos y proyectos socio-políticos" nos referimos al conjunto de fuerzas políticas, valores, discursos, procesos y programas económicos y políticos que en ciertos momentos históricos, por una cierta duración y en contextos específicos pueden llegar a tener una coherencia estructural interna lo suficientemente alta para conformar lo que en la Teoría de la Regulación se llama estructura hegemónica o proyecto hegemónico (Jessop, 1990). Para Europa y América del Norte este tipo de conceptualización ha permitido identificar eras político-económicas como el Fordismo o Post-Fordismo, fases históricas en que era posible identificar coherencia entre regímenes de acumulación capitalista y los modos de su regulación política. Como Jessop (2008) y otros autores elaboraron en trabajos posteriores, de ninguna forma está dado a priori que fuerzas políticas, valores, discursos y programas económicos y políticos forman proyectos hegemónicos, pues aquellos son siempre el resultado de estrategias políticas en disputa. El terreno de disputa por la hegemonía es por un lado el Estado, y por el otro lado, la Sociedad Civil. Un proyecto económico-político que sin duda ha sido hegemónico por varias décadas a nivel internacional, aunque con mucha variación geográfica, ha sido el proyecto neoliberal. El neoliberalismo - como proyecto político - implica según Harvey (2005) la reapropiación del poder por la elite, es decir, hay que entender al neoliberalismo por un lado como un proyecto de clase y de un bloque histórico, y por el otro lado como una estrategia y un proceso, la neoliberalización, entendida como "una estrategia y un proceso que tiene por objeto establecer nuevas formas de acumulación y regulación social a través de la transferencia parcial de la autoridad y / o responsabilidad de la esfera pública a la esfera privada" (Young \& Matthews, 2007:177).

Desde la geografía se ha discutido la necesidad de entender las distintas formas que adquiere el neoliberalismo en lugares concretos (Peck \& Tickell, 2002) y de que manera las relaciones, procesos y políticas territoriales forman parte del proyecto neoliberal y las elites económicas y políticas que lo sostienen. En este sentido, si el neoliberalismo - como proyecto político - implica la reapropiación del poder por la elite, la forma concreta de control territorial que adopta esta reapropiación importa para entender las dinámicas de gobernanza territorial existentes en un territorio. Esta entrada creemos nos permitirá explorar de mejor manera cómo el avance de la idea y práctica de nuevos mecanismos de gobernanza territorial en círculos de políticas públicas responde a la consolidación del proyecto neoliberal de restauración del poder de clase más que a la apertura a nuevos actores en la toma de decisiones.

Para analizar la forma concreta de control territorial adoptada en el marco de proyectos socio-políticos proponemos enfocarse en los dispositivos de territorialización y re-escalamiento. Con esta noción nos referimos a lo que autores como Brenner (2004), en una extensión de la tipología de Jessop (1990) sobre proyectos estatales y estrategias estatales, llaman proyectos estatales espaciales y estrategias estatales espaciales. Ordoñez (2017) explica que los proyectos estatales espaciales son "iniciativas para diferenciar la territorialidad estatal en una geografía regulatoria funcionalmente coordinada, organizacionalmente coherente y dividida en partes, mientras las estrategias estatales espaciales se refieren a estrategias para incidir en la geografía del desarrollo industrial, la inversión infraestructural y el antagonismo y la conflictividad social". 
Los dispositivos de territorialización y re-escalamiento tienen que ver entonces con la división administrativa territorial del Estado, su grado de centralismo o decentralización, que tienen cierta coherencia en ciertos momentos en el tiempo para ponerse en movimiento en otros. Es el Estado que de forma nominativa tiene la autoridad de definir su estructura territorial-escalar, en la práctica estos proyectos y estrategias estatales espaciales son un ensamblaje de múltiples intereses y procesos económicos, políticos y culturales.

Finalmente, y como tercera dimensión, para entender cómo en casos concretos se da, hay que analizar las técnicas, prácticas e instrumentos de intervención territorial con lo que nos referimos a los elementos que autores como Chia et al (2016) ponen al centro de su análisis. Eso sí, con mayor énfasis en las relaciones de poder imbricadas en la gobernanza territorial. Existe una amplia discusión sobre cómo integrar los trabajos de Gramsci y Foucault (Barton, 2008; Sevilla Buitrago, 2014; Sum, 2015), que señala, por un lado, que hay que enfocarse en los actores presentes en ejercicios de gobernanza territorial, de los sectores públicos, privados y de la sociedad civil, en las prácticas y técnicas que emplean y en el carácter de los espacios de negociación, cooperación y deliberación que se instalan. Por otro lado, señalan que hay que situar aquellos elementos, procesos y dimensiones en teorías sobre relaciones de poder en la producción del espacio, para comprender "la articulación de las técnicas territoriales con estrategias políticas más amplias" (Sevilla Buitrago, 2014: 52). El concepto de hegemonía de Gramsci ayuda a conceptualizar la forma en que instancias de gobernanza territorial pueden ser entendidos como instrumentos funcionales a proyectos socio-políticos, de bloques históricos dominantes en ciertos momentos en el tiempo, y que a través del ensamblaje de prácticas discursivas y materiales, tienen la finalidad última de la "legitimación de un determinado proyecto de orden social, facilitando la labor de gobierno - el momento de dominio - mediante la producción de consenso y por tanto la necesidad de coerción y uso de la fuerza" (Sevilla Buitrago, 2014: 54). Mientras el concepto de hegemonía en la línea de Gramsci radica en una concepción del mundo social y político de economía política marxista, localizando el poder en ciertos sectores, elites y bloques históricos, el concepto de gubernamentalidad de Foucault postula el poder como un flujo que circula por la sociedad en su totalidad. El auge del neoliberalismo en este sentido ha sido acompañado de nuevas tecnologías de poder con el efecto de que "esa circulación se hace cada vez más centrífuga gracias a la nueva configuración del Estado como un ensamblaje de prácticas que conectan las instancias de gobierno con los niveles privado y cotidiano a través y en nombre de la libertad, el bienestar de población y su defensa" (Sevilla Buitrago, 2014: 56). En términos tanto ontológicos como metodológicos la combinación de los enfoques de hegemonía y gubernamentalidad, con sus respectivos conceptualizaciones de poder detrás, permite situar la gobernanza territorial en una sociedad donde sí existen clases sociales en disputa, donde además se constituyen bloques históricos con proyectos socio-políticos y dispositivos territoriales específicos, pero donde por el otro lado el poder circula de una forma compleja y multi-direccional, y donde ciertos actores pueden tener más influencia sobre técnicas, prácticas e instrumentos (de intervención territorial) que otros, pero donde el poder en esencia no es algo que se posee, sino algo que tiene que ser producido en procesos de interacción social.

La tabla 1 sintetiza la propuesta teórica que incorpora contextos, dispositivos y prácticas en un marco espacio-temporal de gobernanza territorial. 
Tabla 1: Contextos, dispositivos y prácticas en un marco espacio-temporal de gobernanza territorial

\begin{tabular}{|c|c|c|c|c|}
\hline \multirow[t]{2}{*}{ Dimensión } & \multirow[t]{2}{*}{ Concepto } & \multirow{2}{*}{$\begin{array}{c}\text { Espacio- } \\
\text { temporalidad }\end{array}$} & \multicolumn{2}{|c|}{ Chile } \\
\hline & & & Antiguo & Reciente \\
\hline $\begin{array}{l}\text { Contextos y } \\
\text { proyectos so- } \\
\text { cio-políticos }\end{array}$ & $\begin{array}{l}\text { Bloques histó- } \\
\text { ricos, proyec- } \\
\text { tos socio-polí- } \\
\text { ticos }\end{array}$ & $\begin{array}{l}\text { poca variabli- } \\
\text { dad, alcance } \\
\text { nacional-re- } \\
\text { gional }\end{array}$ & $\begin{array}{l}\text { El proyecto neolibe- } \\
\text { ral original, grandes } \\
\text { grupos económicos } \\
\text { nacionales, discur- } \\
\text { sos de desarrollo } \\
\text { y modernización, } \\
\text { extractivismo y so- } \\
\text { breexplotación de } \\
\text { recursos naturales }\end{array}$ & $\begin{array}{l}\text { Neoliberalismo corre- } \\
\text { gido, grandes grupos } \\
\text { económicos nacionales } \\
\text { y transnacionales. nue- } \\
\text { vo extractivismo, desa- } \\
\text { rrollo sostenible, (crisis } \\
\text { sanitarias, ambientales } \\
\text { y sociales) }\end{array}$ \\
\hline $\begin{array}{l}\text { Dispositivos } \\
\text { de territoriali- } \\
\text { zación y re-es- } \\
\text { calamiento }\end{array}$ & $\begin{array}{l}\text { Proyectos y } \\
\text { estrategias es- } \\
\text { tatales espa- } \\
\text { ciales }\end{array}$ & $\begin{array}{l}\text { mediana va- } \\
\text { riabilidad, al- } \\
\text { cance regio- } \\
\text { nal }\end{array}$ & $\begin{array}{l}\text { Estado centralista, } \\
\text { poca autonomía y } \\
\text { pocos recursos de } \\
\text { regiones y munici- } \\
\text { pios - regionaliza- } \\
\text { ción y decentraliza- } \\
\text { ción, Glocalización }\end{array}$ & $\begin{array}{l}\text { Proyectos de elección } \\
\text { de Gobiernos Regiona- } \\
\text { les, poca autonomía de } \\
\text { municipios, profundiza- } \\
\text { ción de Glocalización }\end{array}$ \\
\hline $\begin{array}{l}\text { Té c n i c a s, } \\
\text { prácticas e } \\
\text { instrumentos } \\
\text { de interven- } \\
\text { ción territo- } \\
\text { rial }\end{array}$ & $\begin{array}{l}\text { Normativas, } \\
\text { Planes y Pro- } \\
\text { gramas }\end{array}$ & $\begin{array}{l}\text { alta variabili- } \\
\text { dad, alcance } \\
\text { regional y lo- } \\
\text { cal }\end{array}$ & $\begin{array}{l}\text { Planes de Desarrollo } \\
\text { Regionales y Comu- } \\
\text { nales, Planes Regu- } \\
\text { ladores Metropoli- } \\
\text { tanos y Comunales, } \\
\text { o Planes de Borde } \\
\text { Costeros }\end{array}$ & $\begin{array}{l}\text { Asociaciones públi- } \\
\text { cas-privadas, Mesas } \\
\text { Redondas Ambientales, } \\
\text { Planes Estratégicos, } \\
\text { Planes Maestros, Foros } \\
\text { Híbridos }\end{array}$ \\
\hline
\end{tabular}

Fuente: elaboración propia

\section{Implementación y evolución del proyecto neoliberal en Chile y sus dispositivos de territorializacion}

\subsection{El proyecto neoliberal y su crisis}

El proyecto neoliberal en Chile se inicia formalmente durante la dictadura militar (1973-1990) mediante la introducción primero de medidas de shock para reactivar la economía (colapsada por el fracaso del modelo industrializador) y luego, con la aprobación e implementación de la Constitución de 1980, que le da sustento jurídico-institucional a los principios fundantes del neoliberalismo en Chile: el principio de subsidiariedad del Estado y el predominio de la propiedad privada en el ámbito económico, el ingreso del mercado a la provisión de derechos sociales (educación, 
salud, pensiones, vivienda) bajo la lógica de la ineficiencia Estatal, valoración de las organizaciones intermedias de la sociedad (apolitizadas y más bien temáticas) en detrimento de los partidos políticos como actores en la toma de decisión.

Algunos autores (Moulian, 1997; Solimano, 2012) argumentan que la radicalidad del proyecto neoliberal chileno fue posible en gran parte por la violencia de la dictadura, que hizo imposible la oposición a estas medidas. Sin embargo, el sistema ha enfrentado instancias de crisis que lo han obligado a reformular y adecuar sus lógicas para garantizar su continuidad en el tiempo. Ejemplo de ello son las medidas tomadas tras la crisis de 1982 que matizó la retirada del Estado de ámbitos clave de la economía, así como en 1987 cuando en un contexto eleccionario y de cambio político, la dictadura tuvo que revertir políticas del entonces ministro Buchi. Una vez instalada la democracia, el eje de las políticas sociales de la concertación fue el implementar acciones que compensaran la desigualdad social y redujeran la pobreza que llegaba casi al $50 \%$ de la población.

Durante los últimos 25 años, los distintos gobiernos han enfrentado las principales contradicciones del modelo: la marcada desigualdad social en un contexto de constante crecimiento económico (Ffrench-Davis, 2003), la desigual distribución geográfica de los procesos extractivo-exportadores (base del modelo económico imperante) en regiones y territorios rurales y los centros de acumulación en la región metropolitana (Daher, 2003) así como, la centralización político-administrativa histórica en un modelo que se basa en la flexibilidad y la libertad de acción individual (Lechner, 1994; Gómez Leyton, 2008). Estas tres contradicciones están en la base de los principales conflictos socio-ambientales que ha vivido el país en los últimos años. Cada una de estas contradicciones apunta a momentos de crisis en dimensiones distintas (social, ambiental y político), pero con una base común: la desconfianza del sistema de instancias de decisión autónomas de los habitantes de los territorios donde se desarrolla la actividad económica.

De este modo, apuntamos a entender las crisis económicas que ocurren en el neoliberalismo, como momentos donde las contradicciones señaladas (desigualdad, acumulación, decisión) impiden u obstaculizan la continuidad del modo de producción imperante, que requiere un nuevo acuerdo social, por lo que entender los mecanismos de toma de decisión se vuelve fundamental.

\subsection{Dispositivos de territorialización: las políticas de regionalización y decentralización}

En esta sección, describiremos la configuración político-territorial del proyecto neoliberal en Chile, representada en el proceso de regionalización iniciado por el gobierno militar, pero implementado y profundizado durante los gobiernos democráticos, para luego entender la espacialidad de las regiones como dispositivo de gobernanza territorial.

Bustos-Gallardo (2014) señala que el proceso de regionalización en Chile implementado en 1976 afectó la capacidad del Estado de intervenir en los territorios, provocando un doble movimiento: por una parte, aumentó la capacidad de atraer inversión hacia las regiones, pero por otra, disminuyó la capacidad de la institucionalidad regional creada de controlar localmente los efectos de esa inversión. Si bien históricamente la relación entre el Estado y las regiones ha estado marcadas por las políticas económicas aplicadas por el Estado - en términos de la capacidad de los territorios a aportar sus recursos naturales a la estrategia de acumulación económica en un 
momento dado - el régimen militar (1973-1990) liberalizó la economía regional y promovió el uso de las "ventajas naturales" de cada región para conectarse a circuitos globales.

En este sentido, y mirando el caso Chileno, Boisier (1988, 1995, 2000, 2004 ) sostiene que las políticas regionales han de entenderse como un triángulo integrado por la organización territorial, la descentralización y la promoción del crecimiento económico y el desarrollo, pasando de un enfoque en la promoción del crecimiento económico durante la década de 1960 y a principios de 1970, a un énfasis en la descentralización económica entendida como la ausencia de control y planificación del Estado, impulsada por la neoliberalización de la dictadura militar de la sociedad chilena. Esto se convirtió en un paradigma que se aplica al proceso de regionalización.

En términos muy concretos, el régimen militar define como principios fundamentales para el proceso de regionalización el promover la ocupación efectiva del territorio nacional, sus recursos naturales y su población, a la vez que velar por la seguridad nacional. Se definen como requisitos para constituir una región: (1) existencia de recursos naturales que apoyan el desarrollo económico del territorio, (2) existencia de población suficiente para sostenerla, (3) tener una estructura urbana-rural capaz de proporcionar servicios básicos para la población mencionada, (4) tamaño debe ser administrativamente eficiente y considerar cuestiones de seguridad nacional. A partir de estos criterios, la Comisión Nacional de Reforma Administrativa (CONARA - Comisión Nacional de Reforma Administrativa) organizó el territorio chileno en trece regiones, de norte a sur (DL 573 y DL 575/1974).

Boisier (2000) sostiene que el esfuerzo de regionalización impuesta por el régimen militar fue una descentralización guiada por la oferta y no la demanda: la descentralización es una necesidad del sistema económico para reconfigurar los circuitos de acumulación, el fortalecimiento de la capacidad de las regiones para integrarse por sí mismos a los mercados globales. En palabras de Boisier " las regiones de Chile se entienden mejor como objetos económicos que entidades orgánicas dotadas de historia y cultura, y carecen de toda expresión política» (Boisier, 2000). Mientras que la configuración de la división administrativa y territorial de las regiones se justifica en los ideales neoliberales, su aplicación se limita y se forma por la lógica de control, lo que dio lugar a una aplicación desequilibrada: la libertad económica es importante para transformar el paisaje, pero existe ausencia de libertad para que los ciudadanos se apropiasen de las nuevas estructuras políticas creadas para administrar las regiones

La falta de participación ciudadana creó una tensión entre la estructura propuesta y las capacidades existentes para llevar a cabo la reforma, que afecta a la identificación cultural con la nueva organización territorial, obligando a las élites y grupos regionales relacionarse con el proyecto nacional, solo a través de su participación en la economía global.

La reforma de 1993, introdujo la elección democrática de las autoridades locales a nivel municipal, pero mantuvo las autoridades regionales (Intendente) bajo la designación directa del presidente, la creación de un consejo asesor del gobierno regional (Consejo Regional) con alguna autoridad administrativa y fiscal, pero sin mayor autonomía fiscal. En general, las reformas se centraron en los niveles políticos locales y de las estructuras de gobierno, y no cuestionaron el enfoque económico de ventajas naturales. En el periodo 1990-2000 las reformas implementadas proporcionaron incentivos fiscales, subsidios, y creación de nuevas estructuras institucionales, 
como las asociaciones público-privadas para aumentar la presencia de los productos regionales en los mercados mundiales. En el periodo 2000-2017 no hubo reformas mayores al sistema de gobierno regional, consolidando un proceso de regionalización que buscó crear instituciones para gobernar el territorio pero no como lugar de toma de decisiones. Los pocos avances de instrumentos técnicos como los reglamentos de ordenamiento territorial o del borde costero, dan cuenta de la incapacidad de los gobiernos regionales de liderar procesos de decisión y gobernanza territorial, y reafirman la hipótesis que la regionalización fue parte del proceso de neoliberalización territorial y configuración de regiones commodity (Bustos-Gallardo \& Prieto, 2019 (forthcoming)) cuyos territorios son parte de una red global de producción, abandonados del Estado central (Floysand et al, 2010).

La neoliberalización - entendida como "una estrategia y un proceso que tiene por objeto establecer nuevas formas de acumulación y regulación social a través de la transferencia parcial de la autoridad y / o responsabilidad de la esfera pública a la esfera privada" (Young \& Mathews, 2007:177) - moldeó los mecanismos de gobernanza regional. en una primera etapa (mediados de 1970), la neoliberalización se centró en la integración de nuevos recursos y regiones a las cadenas globales de producción, sin embargo, creó problemas de gobernabilidad a nivel regional en la toma de decisiones. Como muestra el trabajo de Wetzstein para el caso de Nueva Zelandia (2008:1094) " (la) gobernanza económica local continuará siendo sostenida por estructuras nacionales neoliberales de gobierno».

En el caso chileno, dichas estructuras son la Constitución política del Estado Chileno de 1980 que establece en su artículo 1, que el Estado asumirá un rol subsidiario a las instituciones intermedias quienes tienen garantizada su autonomìa para satisfacer sus fines específicos, y así alcanzar el bien común. Este principio se consolidó con los procesos de creación de nuevos sistemas de salud, educación y previsión social de carácter privado, y la creación de mercados que facilitaran la provisión de aquellos bienes y servicios demandados por la sociedad.

Proponemos hablar de gobernanza territorial neoliberal para insistir sobre el contexto en el estudio de la gobernanza territorial, en una perspectiva analítica. Se busca agregar a los estudios existentes sobre los instrumentos y mecanismos de gobernanza territorial en Chile las tres dimensiones mencionadas anteriormente.

\section{Gobernanza territorial en las Regiones de Antofagasta y Los Lagos: ¿construcción colectiva de visiones territoriales o tecnologías de poder?}

En esta sección nuestro objetivo es analizar dos casos específicos de gobernanza territorial, situados en el contexto socio-político Chileno y sus dispositivos de territorialización y re-escalamiento anteriormente descritos. Si bien las regiones de Los Lagos y Antofagasta presentan particularidades cada una y representan momentos distintos del proceso y las dinámicas de gobernanza territorial, también contienen elementos comunes que permiten evidenciar nuestro argumento sobre la necesidad de considerar las dimensiones de poder que determinan que si bien se configuran acciones e inclusión de nuevos actores, no se cambian las lógicas estructurales de los procesos de toma de decisión. 
El caso de la Región de Los Lagos expone el proceso de la 'Mesa del Salmón', espacio creado por el Gobierno en 2008 para hacer frente a la crisis sanitaria gatillada por el virus ISA. En el caso de la región de Antofagasta, se explica la creación de una asociación público-privada en 2012 Ilamada CREO Antofagasta para la gestión del mejoramiento de la calidad de vida de una ciudad fuertemente influenciada por la minería del cobre.

Nuestro análisis de estos dos casos, sugiere que nuevos mecanismos de gobernanza territorial nacen para reaccionar ante crisis territoriales multi-dimensionales (sanitarias, ambientales, sociales, económicos) que son resultado de dos asuntos relacionados entre sí, por un lado las contradicciones no resueltas del proyecto socio-político neoliberal que se basa en la extracción de recursos naturales y los dispositivos de territorialización y re-escalamiento implementadas. Argumentamos que en los dos casos estudiados, los nuevos mecanismos de gobernanza no nacen para resolver los problemas de fondo del proyecto neoliberal o para repensar los territorios de una forma colectiva (como supone implícitamente la investigación mainstream sobre gobernanza, reproduciendo el problem-solving bias de la teoría de la gobernanza), sino para dar continuidad al modo de producción imperante a la vez que, restaurar la legitimidad de sectores y empresas extractivistas con graves problemas de confianza ciudadana. Estos mecanismos de gobernanza buscan llenar los puntos ciegos entre comunidades afectadas y el sistema político creados por los dispositivos de regionalización y (de-) centralización, implementadas como forma de territorialización del proyecto neoliberal y para gobernar territorios neoliberalizados y glocalizados. Por la forma en que se conciben, diseñan y ejecutan los nuevos mecanismos, en la práctica sirven para acomodar los territorios a necesidades productivas-empresariales.

\subsection{La Mesa del Salmón, Región de Los Lagos}

- El contexto socio-territorial

La Región de Los Lagos en el sur de Chile es uno de los principales productores de salmón del mundo. Desde mediados de los '70s se empezaron a instalar empresas nacionales, consolidándose en los '90s con la llegada de empresas extranjeras y la construcción de una vasta red de infraestructura para la extracción y producción, para alcanzar a inicios del nuevo milenio el segundo puesto en la producción global, tras Noruega. El proceso ha sido descrito por Barton (Barton, 1997; Barton, Gwynne et al. 2008; Barton \& Floysand, 2010) Román (Román, Barton et al., 2015) entre otros, como de una transformación profunda del territorio, economía y cultura regional. Mientras el Estado y la industria lo celebraron como éxito del modelo de regionalización funcionalmente especializada y basada en criterios económicos, la crisis del virus ISA en 2008 planteó cuestionamientos a los efectos y potenciales impactos sociales y ambientales de dicha actividad (Nussbaum, Pavez \& Ramírez, 2012; Peralta, Bebbington et al., 2014), pero también expuso la incapacidad de los espacios regionales o de gobernanza de introducir consideraciones territoriales para resolver las crisis (Bustos-Gallardo, 2013; Irarrazabal, 2014).

\section{- La respuesta a la crisis}

Tras la tardía reacción del Estado, y la aplicación de medidas de contención sanitaria (disposición de las mortalidades, cierre de faenas, cuarentenas, sanitarias, definición de tratamientos fitosanitarios), el Gobierno decidió dar una señal política que abordara los temas de fondo tras la crisis: la fallida capacidad de autoregulación de la industria, y la necesidad del Estado de redefinir 
las reglas del juego para un sector de crecimiento explosivo. La mesa se estableció entonces, como un mecanismo de gobernanza que buscaba crear nuevas instituciones para resolver las contradicciones que el patrón de producción estaba presentando, y si bien estaba oficialmente constituida por representantes del sector público relacionados con la actividad salmonera, liderada por el ex subsecretario de pesca, Felipe Sandoval, se dio cabida a la participación de la industria, sindicatos, ONGs ambientales y toda aquella organización interesada en participar. Durante un mes se reunieron y determinaron una serie de propuestas de acción a implementar por los servicios públicos participantes, que se tradujeron en propuestas de modificación de la Ley de pesca y acuicultura, reglamentos de densidad de aula y antibióticos, líneas de investigación para el Fondo de Investigación Pesquera, entre otras medidas.

Estas medidas apuntaron a los procesos estructurales que sostienen la industria, pero no abordaron los impactos locales inmediatos, como el desempleo, y efecto económico en proveedores de la industria. Para ello el gobierno dispuso recursos a través de líneas de financiamiento CORFO, o del Gobierno Regional como el ISAR (Inversión Sectorial de Asignación Regional). Las peticiones y demandas de actores locales y regionales por ende fueron excluidas de esta instancia, e incluso se dieron por superadas tras la definición de los subsidios de ayuda.

\section{- Proceso de gobernanza y resultados}

Si consideramos la participación de los actores involucrados, desde la perspectiva del Estado, el proceso fue un éxito en cuanto logró contener, encauzar y posicionar nuevas reglas del juego en un sector previamente poco regulado. Los servicios públicos lograron subir los estándares y demandas para la industria, y un mínimo aumento en sus propios recursos para fiscalizar, sin embargo, en 2016 la Contraloría General de la República determinó - a través de una auditoría a sernapesca y subpesca - que ambos servicios no cumplieron con sus labores de fiscalización durante los últimos 6 años, lo que llevó a la realización de varios sumarios administrativos, y prueba que si bien el Estado aparece como ganador del proceso mesa del salmón, no aprovechó de consolidar su autoridad sobre la industria.

En términos de la industria, en general se destaca del proceso la cooperación público-privada y el nuevo marco regulatorio (SalmonChile, 2012). En ese sentido, los empresarios salmoneros lograron una regulación sanitaria clara para la industria, y que el estado se transformase en el garante sanitario de esta regulación. En la formulación de este nuevo modelo institucional la industria salmonera fue consultada y tuvieron un importante grado de incidencia en la etapa pre legislativa y cambio institucional que se derivó de ella, muy por sobre otros actores interesados en participar (Fernández \& Miranda, 2011; Nussbaum, Pavez \& Ramírez, 2012). Sin embargo, estos resultados tuvieron un costo: la división del gremio en dos (con el surgimiento de la Asociación de Productores de Trucha - ACOTRUCH) y el posterior retiro de la principal asociación Salmon Chile de otros grandes productores como AquaChile o Marine Harvest ${ }^{5}$.

Un tercer actor, que se posicionó más bien en una segunda línea pública durante la negociación fue la banca. Dado el nivel de endeudamiento de la industria con la banca, y el problema de

En el caso de AquaChile, su salida se produjo en 2010, pero ya en 2013 regresó al gremio. Marine Harvest se mantiene fuera de la asociación empresarial desde 2016 . 
liquidez de ésta dada la pérdida de masa pesquera, éstos decidieron tener un rol más activo en el proceso de negociación de la solución, a fin de que el nuevo diseño les permitiese recuperar el dinero adeudado. Sus exigencias a la mesa fueron dos: desarrollo de normas sanitarias y fiscalización para la actividad salmonera. Y en segundo lugar, tras percatarse que los peces pueden morir, y por ende no sirven como prenda de garantía, establecieron que el activo de mayor relevancia de las empresas salmoneras eran las concesiones acuícolas. Para hacer eso efectivo requerían poder hipotecar una concesión acuícola, así como también se pudiera generar un sistema de transferencia de estas lo suficientemente dinámico como para generar un mercado de concesiones que fuese rentable para los bancos.

La mesa del salmón concluyó su trabajo en Agosto de 2008 proponiendo una serie de medidas: modificaciones al Reglamento Ambiental Acuicultura y al Reglamento Sanitario de la Acuicultura, regulando la importación de ovas, y promoviendo el establecimiento de "barrios" que permitiésen la sincronización de ciclos productivos a fin de facilitar el control y manejo sanitario. Estos cambios se materializaron en modificaciones a la Ley General de Pesca y Acuicultura a principios del año 2010, y en 19 modificaciones reglamentarias. Para el año 2013 la industria salmonera produjo sobre 700 mil toneladas nuevamente, lo que da cuenta de que la crisis al menos en términos productivos, fue superada.

La efectividad de estas medidas, y en especial de los barrios es cuestionada hoy por la comunidad científica, movimientos ambientales, y sociales, ya que los barrios intensifican el carácter monocultor de la región, por lo que en realidad se está manteniendo el patrón productivo que llevó a la crisis.

La mesa del salmón constituyó en este sentido, una forma de gobernanza ambiental neoliberal que facilitó la implementación de otros mecanismos de gobernanza neoliberal: privatización (a través del establecimiento de las concesiones como hipotecables), cercamiento (a través del establecimiento de barrios) y valorización (a través de nuevas medidas sanitarias). Lo que se muestra este caso es que las soluciones apuntaron más bien a reforzar los circuitos de acumulación rotos, pero sin transformar las relaciones sociales de fondo que fueron construidas durante el crecimiento y auge de la industria salmonera.

De este modo la mesa del salmón simbolizó la coalición estado-empresas salmoneras-bancos, con la meta de recuperar la industria salmonera. Lo particular de esta situación es que si bien el Estado definió a la Mesa del Salmón como pública, y participaron de forma vinculante solamente organismos tales como Ministerio de Economía, SUBPESCA, Subsecretaría de marina, CORFO y CONAMA (Nussbaum, Pavez \& Ramírez. 2012). Estos autores afirman que la conformación de la mesa obedece a la situación de crisis y a la urgencia de generar un cambio institucional lo antes posible, sobre todo por los requerimientos de los bancos. En la práctica se optó por gente de confianza, más que por conocimientos especializados, lo que queda matizado en que el único académico que participó en la mesa fue un reconocido investigador que asesoraba en temáticas ambientales al Ministerio de Economía, no obstante, era especializado en algas y desconocía la temática salmonera.

Un aspecto importante a destacar es que si bien distintos grupos participaron en la instancia, fue el sector empresarial quien tuvo una comunicación más activa en ella. En efecto, esta es la condición clave que definirá que el gremio salmonero definiese el contenido del cambio institu- 
cional, a partir del documento elaborado por INTESAL denominado "44 medidas para afrontar la crisis sectorial".

\subsection{La iniciativa CREO Antofagasta, Región de Antofagasta}

\section{- El contexto socio-territorial:}

La Región de Antofagasta en el norte de Chile es el centro de la importante industria minera del país y cuenta con las reservas de cobre más grandes del mundo. La ciudad de Antofagasta, la capital y el centro funcional de la región, se desarrolló de una pequeña ciudad empresarial fundada por la industria del salitre a fines del siglo 19 a una de las ciudades portuarias exportadoras y de logística minera más importantes del continente (Arias et al., 2013; Phelps \& Atienza, 2015). El proyecto socio-político neoliberal y los dispositivos de territorialización y re-escalamiento del país profundizaron sus efectos sobre la región a partir de los años noventa, cuando en la región se instalaron una gran cantidad de proyectos mineros transnacionales. De esta forma, entre 1990 y 2008 , la región recibió entre $15 \%$ and $30 \%$ de toda la inversión extranjera directa en Chile, asociada a empresas transnacionales como BHP Billiton, Anglo American, Xstrata y Barrick Gold (Aroca \& Atienza, 2008, 2011). Mientras por el auge de la actividad minera transnacional hoy en día la región cuenta con el PIB más alto del país, de forma paralela muestra problemas típicos de las economías de enclave minero que han llevado a la región, y la ciudad de Antofagasta, a un momento de un simultáneo boom minero y una crisis social y ambiental.

\section{- El momento de crisis:}

Esta crisis social y ambiental en la región tiene varias dimensiones y expresiones. Por un lado, hay un sentido generalizado en la región acerca de tener que aguantar los impactos de la actividad minera pero no participar de los beneficios. Gran parte del BIP tan alto se esfuma al extranjero y a Santiago, donde las empresas mineras tienen su sede y donde viven sus gerentes. La introducción de los turnos $7 \times 7$ agravó esa fuga de capital de la región. Por el otro lado, la inversión pública y privada en la región, y en especial sus principales ciudades Antofagasta y Calama, se ha concentrado en la actividad minera y su infraestructura logística y de abastecimiento. Un ejemplo es que los cuatro puertos de la región exclusivamente se orientan hacia la minería, bienes de consumo y alimentos para la población en general son transportados a Antofagasta por camión desde otros lados y puertos del país. En general, las ciudades de Antofagasta y Calama cuentan con un pobrísimo equipamiento con vista a infraestructura civil, de educación, salud, deportes, espacios públicos y verde. Los mercados de vivienda tienden a inflarse con el dinero minero, que en conjunto con un masivo aumento de inmigración nacional e internacional lleva al crecimiento más alto del país de campamentos y personas que viven en ellas. En Calama la crisis estalló con masivas movilizaciones ciudadanas en 2012, explícitamente cuestionando el centralismo del país en términos políticos por un lado y distribución de la riqueza minera por el otro, en Antofagasta en 2013, gatillado por la construcción de un nuevo centro de acopio de cobre en el mismísimo centro de la ciudad, en aquello acusando el grave e histórico problema de contaminación minera y además un sistema de ordenamiento territorial a nivel regional y planificación urbana, no existente en el primer caso e inoperante en el segundo. 
- La respuesta a la crisis:

Tanto en Calama como en Antofagasta la respuesta a la crisis fue la implementación de nuevos mecanismos de gobernanza territorial, Calama Plus y CREO Antofagasta. Esta última iniciativa nace al año 2012 y tiene el objetivo de "enfrentar el desafío de crecimiento que tiene la ciudad, con un fuerte sentido de mejora en la calidad de vida de la comunidad", proyectando la ciudad futura "a través de un Plan Maestro que propone el crecimiento urbano sostenible de Antofagasta, al año 2035" (Homepage CREO Antofagasta). Además, se formula "el propósito de construir una ciudad modelo a nivel nacional e internacional", para lo cual se implementa "un sistema de gobernanza público-privada que incluye a actores del Gobierno Regional, la Ilustre Municipalidad de Antofagasta y la comunidad organizada, para que en un dialogo participativo converjan las necesidades y expectativas de todos quienes que formamos parte de nuestra ciudad". Distinto al caso de la Mesa del Salmón, en Antofagasta la iniciativa nace directamente del sector privado, en particular por parte de la empresa minera más grande del mundo, BHP Billiton que, a través de su filial local, Minera Escondida, opera el yacimiento minero privado más grande del país.

\section{- $\quad$ La estructura/el proceso de gobernanza:}

En acorde con el espíritu declarado de alianza pública-privada se estableció un complejo esquema institucional de gobernanza. En un "nivel estratégico" existe un consejo público-privado que lideran la alcaldía y la intendencia y donde participan además alrededor de 40 miembros de los sectores públicos-privados. Se junta tres veces al año y su función es promover y facilitar el cumplimiento de los objetivos del plan. A un "nivel táctico" está el comité ejecutivo que consiste de diez integrantes y que se junta entre 6 y 12 veces al año. Participan las dos Universidades locales más importantes, 6 representantes del sector privado, 4 miembros del consejo ciudadano y la secretaría ejecutiva de CREO. Esta última instancia, la secretaría ejecutiva que lidera la iniciativa a nivel cotidiano, está a cargo de dos urbanistas. Aparte de los niveles descritos, el esquema de gobernanza considera la participación de un panel de expertos internacionales (como el ex-alcalde de Bogotá Enrique Peñalosa y un representante de la OCDE), un consejo ciudadano (donde participan representantes de alrededor de 30 organizaciones ciudadanas) y un consejo de donantes (Minera Escondida and BHP Billiton). Éste último es el "actual directorio, pues aprueba proyectos y su financiamiento, son el mandante de CREO" (entrevista con miembro de CREO).

Entre 2012 y 2013 el objetivo del trabajo fue el diagnóstico de los problemas territoriales, la elaboración de una línea base y la implementación de proyectos de confianza. Entre 2013 y 2014 se iba a desarrollar la visión y el Plan Maestro, y a partir de 2015 a implementar los proyectos estratégicos. En la práctica el desarrollo ha sido más lento, hasta el día de hoy por ejemplo no existe un Plan Maestro, sí se ha concluido el diagnóstico y se están implementando proyectos.

- Resultados del mecanismo/proceso de gobernanza:

Acerca de CREO Antofagasta es importante destacar que se trata de una iniciativa de largo plazo, con horizonte de 2035, es decir, hay que tener cautela en hablar de resultados del proceso en este estado temprano de la iniciativa. Sin embargo, podemos delinear algunas tendencias y aspectos estructurales. Primero, aunque han habido amplios procesos de participación ciudadana, 
estos han sido más bien limitados en su influencia sobre las prioridades que se definen y los proyectos que se ejecutan. Los momentos de diagnóstico y de construcción de agendas de acción claramente son espacios en que se produce poder, pues se instalan visiones comunes y discursos que condicen los marcos de las discusiones y las acciones futuras por tomar. A modo de ejemplo, las recomendaciones del Movimiento Amplio de Acción Ciudadana (MACC) acerca de un salario mínimo, un impuesto regional minero y el abordaje de los problemas de contaminación y salud pública no han sido tomados en cuenta. En cambio, los lineamientos generales y los proyectos ejecutados y proyectados hasta el momento abordan cuestiones mucho menos polémicos, menos estructurales, más culturales y económicos por un lado y más urbanísticos-técnicos por el otro. Ejemplos son la implementación de una agenda cultural, de eventos culturales y deportivos, una competencia para emprendedores locales, la limpieza de microbasurales y la pintura participativa de fachadas en algunos sectores pobres de la ciudad. Proyectos urbanísticos más ambiciosos tienen que ver con la reestructuración y modernización del borde costero, la construcción de una amplia red de ciclovías y la construcción de paseos cerro-mar. Estos proyectos sin duda cambiarán la cara de la ciudad a futuro y serán en este sentido más exitosos que proyectos sectoriales previamente existentes. La razón es que CREO efectivamente actúa como coordinador y moderador entre distintos intereses territoriales y sobre todo articula inversiones públicas (de distintos sectores) y privadas (de empresas mineras), eso, sí, en última instancia lo hace en función de los intereses del mandante de la iniciativa, la industria minera. En varias entrevistas con profesionales de CREO se mencionó que la última palabra sobre el presupuesto y el financiamiento de ciertas iniciativas la tiene BHP, y que claramente no se ejecutan obras ni se debaten temas que van en contra de sus intereses. $Y$ este interés tiene que ver con adecuar la ciudad a los desafíos de futuro con vista a su rol como base productiva y logística para la actividad minera. En varias entrevistas se mencionó que por un lado hay que mejorar los flujos de bienes y personas a través del espacio urbano y que por el otro lado "hay que ser capaz de atraer capital humano avanzado en un contexto en que ciudades mineras compiten entre sí a nivel global y dónde el trabajo es cada más especializado" (entrevista). Por el hecho de que los yacimientos mineros privados en la Región de Antofagasta aún tienen una larga vida, la intervención territorial se transforma en un interés estratégico de las empresas a su cargo e instrumentos como CREO Antofagasta sirven, aparte de la adecuación del espacio urbano a sus necesidades productivas, para "crear valor compartido y relaciones comunitarias de largo plazo para de esta forma ganar y mantener legitimidad social" (Devenin, 2017: 6), en las palabras de sus promotores.

\section{Conclusión}

Nuestro análisis de dos casos de iniciativas de gobernanza territorial en Chile, (la Mesa del Salmón realizada entre 2008-2010 que afectó la actividad en la Región de los Lagos y la iniciativa CREO Antofagasta implementada desde 2012 a hoy en la Región de Antofagasta), sugiere que nuevos mecanismos de gobernanza territorial nacen para reaccionar ante crisis territoriales multi-dimensionales (sanitarias, ambientales, sociales, económicos). Esta reacción, es resultado de dos asuntos relacionados entre sí, por un lado, las contradicciones no resueltas del proyecto socio-político neoliberal, que se basa en la extracción de recursos naturales y por otro, los dispositivos de territorialización y re-escalamiento implementados. 
Argumentamos que en los dos casos estudiados, los nuevos mecanismos de gobernanza no nacen para resolver los problemas de fondo del proyecto neoliberal o para repensar los territorios de una forma colectiva (como supone implícitamente la investigación mainstream sobre gobernanza, reproduciendo el problem-solving bias de la teoría de la gobernanza), sino que, para dar continuidad al modo de producción imperante y restaurar la legitimidad de sectores y empresas extractivistas con graves problemas de confianza ciudadana.

Estos mecanismos de gobernanza buscan llenar los puntos ciegos entre comunidades afectadas y el sistema político contenido en los dispositivos de regionalización y (de-) centralización, mediante el cual, se gobiernan territorios neoliberalizados y glocalizados. Es decir, mientras la institucionalidad atribuye responsabilidad de planificación territorial a las regiones, y a los gobiernos regionales, sin dotarlos de recursos efectivos para ello, las soluciones se discuten y acuerdan en instancias que no tienen la capacidad efectiva de implementar o dar seguimiento a la implementación de dichos acuerdos. En otras palabras, los nuevos mecanismos se conciben, diseñan y ejecutan, para acomodar los territorios a necesidades productivas-empresariales.

Los casos estudiados son situaciones de crisis, en las cuales se desplegaron mecanismos e instrumentos de gobernanza para pacificar y controlar el territorio neoliberalizado, en cambio, las crisis mostraron la dimensión territorial del modelo extractivista y sus consecuencias ambientales-sociales y económicas, aumentando el malestar tanto con la industria como con las autoridades territoriales.

Para concluir, proponemos que, para enfrentar los desafíos conceptuales y metodológicos en el estudio de la gobernanza territorial, es necesario dejar una mirada neutra sobre los instrumentos y procesos, y avanzar hacia una perspectiva crítica, que considere el contexto en que se implementan y las relaciones de poder que las sustentan.

\section{Referencias}

ARIAS, M.; ATIENZA, M. \& CADEMARTORI, J. Large mining enterprises and regional development in Chile: Between the enclave and cluster. Journal of Economic Geography, 2014, No1, Vol. 14, p. 73-95.

AROCA, P. \& ATIENZA, M. La Conmutación Regional en Chile y su Impacto en la Región de Antofagasta. EURE Revista Latinoamericana de Estudios Urbano Regionales, 2008, N0102, Vol. XXXIV, p. 97-121.

AROCA, P. \& ATIENZA, M. Economic implications of long distance commuting in the Chilean mining industry. Resources Policy, 2011, No3, Vol. 36, p. 196-203.

BARTON, J. R. ¿Revolución Azul? El impacto regional de la acuicultura del salmón en Chile. EURE Revista Latinoamericana de Estudios Urbano Regionales, 1997, № 68, Vol. XXII, p. 57-76.

BARTON, J. El Poder de la Gobernanza: el 'eslabón perdido' de la sustentabilidad urbana, En: YAÑEZ, G. et al. (eds.): Ciudad, Poder, Gobernanza, Santiago: EURElibros, 2008, p. 413-430. 
BARTON, J. R. \& FLOYSAND, A. The political ecology of Chilean salmon aquaculture, 1982-2010: A trajectory from economic development to global sustainability, 2010. Global Environmental Change-Human and Policy Dimensions, N²4, Vol 20, p. 739-752.

BARTON, J. R.; GWYNNE, R. N. \& MURRAY, W. E. Transformations in resource peripheries: an analysis of the Chilean experience. Area, 2008, No1, Vol 40, p. 24-33.

BEVIR, M. Governance. A Very Short Introduction. Oxford: Oxford University Press, 2012.

BOISIER, S. Palimpsesto de las regiones como espacios socialmente construidos. Santiago de Chile: I. L. y. d. C. d. P. E. y. S. -ILPES, 1988.

BOISIER, S. Regiones pivotales y regiones virtuales, posmodernismo territorial y globalización. Revista Foro, 1995, №25.

BOISIER, S. Chile: la vocación regionalista del gobierno militar. EURE Revista Latinoamericana de Estudios Urbano Regionales, 2000, № 26, p. 81-107.

BOISIER, S. Desarrollo territorial y descentralización: El desarrollo en el lugar y en las manos de la gente. EURE Revista Latinoamericana de Estudios Urbano Regionales, 2004, No90, Vol 30, p. 27-40.

BOISIER, S. El lenguaje emergente en desarrollo territorial C. Centro de Anacción (Análisis y Acción) Territorio y Sociedad, 2009.

BRENNER, N. Urban governance and the production of new state spaces in Western Europe, 19602000. Review of international political economy, 2004, No3, Vol 11, p. 447-488.

BRIDGE, G. \& PERREAULT, T., Environmental Governance. En: CASTREE, N; DEMERITT, D.; LIVERMAN, D. \& RHOADS, B. A companion to environmental Geography. West Sussex: Blakwell, 2008, p. $475-497$.

BUSTOS-GALLARDO, B. The ISA crisis in Los Lagos Chile: A failure of neoliberal environmental governance? Geoforum, 2013, Nº48, p. 196-206.

BUSTOS-GALLARDO, B. Intervención estatal en contextos de crisis. El caso del virus isa, la industria salmonera y la región de Los Lagos, Chile. Revista Geografíca del Sur, 2014, No7, Vol 5, p. 77-94.

BUSTOS-GALLARDO, B. \& PRIETO, M. Nuevas aproximaciones teóricas a las Regiones-commodity desde la ecología Política. EURE Revista Latinoamericana de Estudios Urbano Regionales, 2019 (forthcoming).

CHIA, E.; REY-VALETTE, H.; MICHEL, L.; SOULARD, C. T.; NOUGAREDES, B.; MATHÉ, S.; BARBE, E.; MAUREL, P.; JARRIGE, F. \& GUIHÉNEUF, P.-Y. Proposición metodológica para el análisis de la go- 
bernanza territorial a partir de una experiencia francesa. Revista Geográfica de Valparaíso, 2016, No53, p. 23-46.

DAHER, A. Regiones-commodities. Crisis y contagio en Chile. EURE Revista Latinoamericana de Estudios Urbano Regionales, 2003, No86, Vol 29, p. 89-108.

DEVENIN, V., How Companies Can Support Their Regions through Collaborative Community Development. Primer Network for Business Sustainability Chile, 2017.

DE MATTOS, C. A. De la planificación a la governance: implicancias para la gestion territorial y urbana. Revista Paranaense de Desenvolvimento, 2004, No 107(Julio-Diciembre), p. 9-23.

DELAMAZA, G. \& THAYER, L. E. Percepciones políticas y prácticas de participación como instrumento para la gobernanza de los territorios. EURE Revista Latinoamericana de Estudios Urbano Regionales, 2016, N0127, Vol 42, p. 137-158.

DUFFY, R. Non-governmental organisations and governance states: The impact of transnational environmental management networks in Madagascar. Environmental Politics, 2006, No5, Vol 15, p. 731-749.

FERNANDEZ, M. \& MIRANDA, D. Coaliciones, dinámicas territoriales y desarrollo: el caso de la coalición salmonera en Chiloé Central. Documento Nº108, RIMSIP, 2011.

FIGUEROA, R. \& CHIA, E. Introducción al número especial Gobernanza territorial, conflictos y aprendizajes. Revista geográfica de Valparaíso, 2016, № 53, p. 1-6.

FLØYSAND, A.; BARTON, J. R. \& ROMAN, A. La doble jerarquía del desarrollo económico y gobierno local en Chile: El caso de la salmonicultura y los municipios chilotes. EURE Revista Latinoamericana de Estudios Urbano Regionales, 2010, N0108, Vol 36, p. 123-148.

FFRENCH- DAVIS, R. Entre el neoliberalismo y el crecimiento con equidad. Santiago: CEPAL y LOM Ediciones, 2003.

GÓMEZ LEYTON, J. C. Política y ciudadanía en una sociedad neoliberal avanzada, Chile 1990-2007. Cuadernos del CENDES, 2008, No67, Vol 25, p. 59-83.

HARVEY, D. A brief History of Neoliberalism. Oxford: Oxford University Press, 2005.

HIDALGO, R. \& ZUNINO, M. La urbanización de las áreas periféricas en Santiago y Valparaíso: el papel de las relaciones de poder en el dibujo de la geografía socioresidencial. EURE Revista Latinoamericana de Estudios Urbano Regionales, 2011, N0111, Vol 37, p. 79-105.

IRARRAZABAL, F. ¿Peces gordos y peces pequeños? Las empresas salmoneras y el cambio institucional en acuicultura post crisis del virus ISA. Universidad de Chile: Magister en Ciencia Política, 2014. 
JESSOP, B. State theory: Putting the capitalist state in its place. Pennsylvania: Penn State Press, 1990

JESSOP, B. State Power: A Strategic-Relational Approach. Oxford: Blackwell, 2008.

JORDAN, A. The Governance of Sustainable Development: Taking Stock and Looking Forwards. Environment and Planning C, 2008, No. 1, Vol. 26, p. 17-33.

LECHNER, N. Chile 2000: las sombras del mañana. Estudios Internacionales, 1994, No105, p. 3-11.

LUKAS, M. Urban Governance. En: ORUM, A. (ed.), The Wiley-Blackwell Encyclopedia of Urban and Regional Studies. Hoboken, NJ: Wiley-Blackwell, 2019 (forthcoming).

MANSFIELD, B. Thinking through Scale: The Role of State Governance in Globalizing North Pacific Fisheries. Environment and Planning A: Economy and Space, 2001, No10, Vol 33, p. 1807-1827.

MAYNTZ, R. Nuevos desafíos de la teoría de la gobernanza. En: CARRILLO I MARTíNEZ, A. (coord.), La gobernanza hoy, 2005, p. 83-98.

MCCARTHY, J. The financial crisis and environmental governance 'after' neoliberalism. Tijdschrift Voor Economische En Sociale Geografie, 2012, №2, Vol 103, p. 180-195.

MOULIAN, T. Chile Actual: Anatomia de un mito. Santiago de Chile: LOM Ediciones, 1997.

NUSSBAUM, I.; PAVEZ, C. \& RAMÍREZ, E. Crisis del virus ISA y la nueva institucionalidad en Chiloé. En: OSPINA. P. \& HOLLENSTEIN, P. Jamás tan cerca arremetió lo lejos. Inversiones extraterritoriales, crisis ambiental y acción colectiva en América Latina. Quito: Universidad Andina Simón Bolívar, 2012, p. 121- 138.

NUISSL, H.; HÖHNKE, C., LUKAS, M.; DURÁN, G.; HÖLZL, C.; RODRIGUEZ SEEGER, C. Megacity Governance - Challenges and Approaches, En: HEINRICHS, D. et al. (eds.). Risk Habitat Megacity. Verlag Berlin Heidelberg : Springer, 2012, p. 87-110.

ORDOÑEZ, S. Estado y Neo-Desarrollismo en Sudamérica: Hacia un balance crítico. Revista Estado y Políticas Públicas, 2017, No 9, p. 123-143.

PECK, J. \&TICKELL, A. Neoliberalizing space. Antipode, 2002, No3, Vol 34, p. 380-404.

PERALTA, P. O.; BEBBINGTON, A.; HOLLENSTEIN, P.; NUSSBAUM, I. \& RAMÍREZ, E. Extraterritorial Investments, Environmental Crisis, and Collective Action in Latin America. World Development, 2014, Vol 73, p. 32-43.

PERREAULT, T. State restructuring and the scale politics of rural water governance in Bolivia. Environment and Planning A, 2005, No2, Vol 37, p. 263-284.

PHELPS, N.; ATIENZA, M. \& ARIAS, M. Encore for the enclave: The changing nature of the industry enclave with illustrations from the mining industry in Chile. Economic Geography, 2015, №2, Vol 9, p. 119-146. 
PIERRE, J. Comparative Urban Governance. Uncovering Complex Causalities. Urban Affairs Review, 2005, No4, Vol 40, p. 446-462.

ROMÁN, A; BARTON, J.R.; BUSTOS, B. \& SALAZAR, A. (eds.) Revolución salmonera: paradojas y transformaciones territoriales en Chiloé. Santiago de Chile: RIL Editores, 2015.

SALMON CHILE. Chilean Salmon industry brief, 2012.

SERRANO, C. Gobernanza para el desarrollo económico territorial en América Latina. Santiago de Chile: Rimisp, 2011.

SEVILLA-BUITRAGO, A. Hegemonía, gubernamentalidad, territorio. Apuntes metodológicos para una historia social de la planificación. EMPIRIA. Revista de Metodología de Ciencias Sociales, 2012, No 27, p. 49- 72.

SOLIMANO, A. Chile and the neoliberal trap: the post-Pinochet era. Cambridge: Cambridge University Press, 2012.

SUM, N.-L. Cultural Political Economy of Competitiveness, Competition and Competition Policy in Asia. Distinktion: Scandinavian Journal of Social Theory, 2015, No2, Vol 16, p. 211-228.

TORRE, A. El rol de la gobernanza territorial y de los conflictos de uso en los procesos de desarroIlo de los territorios. Revista Geográfica de Valparaíso, 2016, № 53, p. 07-22.

WETZSTEIN, S. Relaunching regional economic-development policy and planning for Auckland: remaking the state and contingent governance under neoliberalism. Environment and Planning C: Government and Policy, 2008, No6, Vol 26, p. 1093-1112.

YOUNG, N. \& MATTHEWS, R. Resource economies and neoliberal experimentation: the reform of industry and community in rural British Columbia. Area, 2007, No2, Vol 39, p. 176-185.

\section{Agradecimientos}

ECOS-Conicyt C15HO3

Fondecyt Regular 1160848

Fondecyt iniciacion 11150789 
